\title{
16
}

\section{FORECASTING FUTURE TRAJECTORIES FOR IMMERSIVE JOURNALISM}

\author{
Turo Uskali, Astrid Gynnild, Esa Sirkkunen, \\ and Sarah Jones
}

In this book we have critically explored the emerging practices of immersive journalism. In the news business, experimenting with new forms of storytelling has become the new normal. After spending a decade to get familiar with simple virtual reality tools, however, the future of immersive journalism is still considered uncertain. Immersive storytelling appears to become more concentrated on special events and locations. Journalistic virtual reality skills are increasingly crafted away from the newsrooms by small and specialized subcontractors. SponsoringVR by the big tech companies tends to diminish in parallel with a growing move towards augmented reality investments.

An early VR experiment by the Finnish Broadcasting Company (YLE) highlights some crucial challenges with implementing VR within news. In 2019, the public broadcaster funded a VR experience that imitated the first explosion of the hydrogen bomb Ivy Mike in 1952 in the Pacific Ocean. The video was produced by Tea Time Productions and promoted in YLE's main news program. The piece experiment was heavily criticized and considered a waste of time. It was too difficult for the viewers to grasp what was going on. In the broadcast the journalist wore the head-mounted display and moved around the studio, whilst the background showed the atoll and the explosion. Users could also download the video from the broadcaster's website. The only dilemma was that most people in the audience did not own high-end VR devices, so later on YLE decided to offer the video experience at various events such as city fairs. The strategy was clear: to create the experience, demonstrate it in a traditional news format, then offer as a download and allow more people to experience the video in exhibition formats. The strategy uncovered the difficulties of promoting new visual technologies on established platforms. Television obviously cannot really support VR affordances such as presence and immersion. Additionally, the TV audience got the feeling of being ignored for a few valuable minutes by the public broadcaster. 
In science and technology studies there is a growing interest in understanding the social consequences of technologies more reflectively. Lievrouw (2014, 46-47) sketches a triad of artifacts, practices, and arrangements with which we can start to seek answers to the slow development of VR technology in a broader societal context.

As a thought experiment, we apply this model to the existing research findings of this book. An important aspect of VR as material artifacts is the poor usability of the low-end VR devices. The HMDs have been rather clunky to use, the visual footage has been blurry, audio monaural, etc. The offering of free cardboard HMDs was a sympathetic, shoelace-budget idea to introduce users to this new medium, but it came at a price. The smartphone can slide away easily from the cardboard, the footage is rather fuzzy, and the feeling of immersion limited. These experiences may partly explain the low interest in VR content or devices. In addition, fears of simulation sickness, especially when using low-end devices, has made users suspicious and less eager to try new gadgets. Chapter 11 on the hierarchy of user experience articulated clearly the importance of understanding the material usability of VR artifacts.

The usability of VR devices has been previously up for discussion as well. The technological lag between expectations and reality created much disappointment during the second appearance of VR in the 1990s (Evans 2019). The costs of highend devices with better usability have remained high. Thus, VR is still far from being the democratic medium as was previously predicted.

Following Marshall McLuhan's famous tetrad of media effects (McLuhan \& McLuhan 1988), we can ponder what kind of media practices the use of VR would render obsolete? Television still has important cohesive meaning in modern societies, although cloud-based services like Netflix have been challenging the ritualistic television usage. The good side of conventional TV is that it allows multitasking, which is, at the moment, impossible with VR. The social applications of VR are limited compared to social media apps. Users are left mostly alone in the VR environment, although AltSpaceVR and Facebook Spaces exemplify attempts to make VR more social. Therefore, we predict that VR as a practice starts as a complementary, rather than an eliminatory, media practice.

Journalism follows its own production logics and ethics. The ethical premises of accuracy and transparency create tensions among journalists about how to be ethical storytellers in the virtual reality universe. Being transparent means making the users understand how immersive technologies work and how the users are affected by them. The underlying idea is that when users become moreVR-literate they will become aware of the epistemic differences between genres such as immersive news and more interpretative immersive documentaries.

When thinking about arrangements and institutions, we enter into the world of digital economy. The global techno-giants' Google, Facebook, Microsoft, and Samsung drive towardsVR is a continuation of their general battle for market dominance of the emerging consumerVR market and the future of the digital economy, as Evans $(2019,46)$ states. The already functioning VR platforms demonstrate how the relations between users and companies are being arranged. When building is 
closed, proprietary platforms are able to control the contents and collect data from the reactions of users - as they have been doing with various other services. If the business model of data collection is transferred into VR usage, the concerns around privacy and user-profiling become paramount also in this field. The situation resembles the process around 2006-2008 when the social media platforms were established without public knowledge about their business model and its consequences. In the same way the platforms are setting the field and controlling the emerging practices of VR. However, structures and norms on how to regulate this new medium are still far into the future.

Our experiment with Lievrow's model shows that inVR there is much improvement to be made. The material artifacts must be easier to use to become part of our daily practices. Immersive journalism needs to further develop storytelling approaches that are in alignment with journalism principles of accuracy and transparency. The affordances of technology and journalism are challenged to merge in new ways. At the same time, some kind of regulation is needed to protect the users from emotional manipulation and exploitation. To a large extent the giant tech companies rule out the emerging practice for immersive technologies in journalism as well as in other business, without too much interference from the content producers themselves.

From the time that podcast was first developed as an immersive medium, it took ten years before it was adopted by journalism. The main factors that contributed to the breakthrough were: interesting content, enthusiastic producers, usable and widespread technology, users who knew how to use the devices, cloud services, fast connections, and channels of distribution that are independent of the producers of technology (Hammersley 2004; Berry 2015; Berry 2016; Bottomley 2015).

\section{Future trajectories}

In the years to come immersive journalism might gravitate in different directions depending on the variables above and more. We conclude this book by suggesting six potential trajectories for the adoption and adaption of immersive technologies in journalism in the near future.

\section{Researching audiences will open new avenues for development}

The question at the heart of any journalism scenario lies in the audience. There has been plenty of "buzz" in the aftermath of Milk's TED talk in 2015, and also in the impact of the New York Times' NYTVR app, which was the most downloaded on its first weekend in the same year (Jaekel 2015). But what happened to longevity? Has immersive journalism found a growing audience or are the enthusiasts still searching for more users?

An ImmerseUK survey in 2018 found that "audiences loved that they had their own story to take away with them - something they did rather than something they 
saw" (ImmerseUK 2018, 10). The challenge is getting them into the spaces to view stories in the first place. The survey also found that of all of the immersive pieces studied, from education to gaming to social, the most popular in the audience were the perspective-shifting pieces. These videos were mostly found in immersive journalism or documentary formats. These were the Iexperiences, exemplified through videos such as Clouds Over Sidra (Milk 2015) and In My Shoes: Intimacy (Gauntlett 2016), that created physiological feelings in the audience, for instance heart rates increasing. The impact that immersive experiences have on an audience is clear: "Participants explained in discussion that they were 'in' rather than simply watching a story".

Another study found that immersive journalism in which there was an element of perceived interactivity, with a character making direct eye contact with the viewer, engaged users more often and for longer periods of time. The study (Steed et al. 2018) used an immersive journalism experience by the BBC called "We Wait". Nick North, Director of Audiences at the BBC, said: "whilst this was a small study, a 25 percent conversion rate from the We Wait VR experience is very impressive, and potentially indicative of the significant impact VR could have at scale" (Steed et al. 2018).

A recent study of users' impressions of and reactions to immersive journalism in virtual reality found that users think VR can add considerable value to mainstream journalistic productions, potentially boosting engagement and trust (Nielsen \& Sheets 2019).Through a study utilizing a use-and-gratifications framework, focus groups looked at different immersive experiences. Even though they were critical towards the technology itself, they saw a potential within journalism.

One particular concern raised in this study is echoed in other studies and in anecdotal evidence collected at various VR events, namely the social perception of VR. Users feel embarrassed when putting on a headset. It is an isolating experience and one that can make people feel self-conscious. A study by the BBC found a similar audience concern, which suggested that the limitations were the "clunky user experiences of the headsets" (Watson 2017,37). To sum up, just because a story is told on the platform, it may not be told in the way most users want to receive it. The various media technologies are to a large extent complementary platforms and not actually competitors; users have different preferences and there is no longer a "one size fits all".

In a year-long study as an RJI Fellow at the University of Missouri, Euronews' Thomas Seymat set out to develop tools that would facilitate audience research for 360-degree or VR content. He wanted to provide evidence-based best practices for immersive storytelling. By interviewing immersive journalists, he found that 41 percent either agreed or strongly agreed that they knew what their audience liked. Only 30 percent knew what their audience wanted. Right here we have a gap in knowledge. To determine where immersive journalism is going, how it is to be experienced, and how narratives are formed, we need more research in order to understand. Seymat is creating tools to help immersive journalists get better 
audience feedback. If we are to see immersive journalism thrive, we think that such tools are needed across the industry.

\section{Authenticity and transparency remain core values of immersive journalism}

Questions of authenticity in immersive journalism stories are essential. Already in the first immersive journalism experience by Nonny de la Peña, Hunger in LA (2012), authentic audio recordings and animation were used to reconstruct the human drama at a food bank line. When The New York Times produced its first immersive journalism documentary, The Displaced, in 2015, the critics, mostly from other news media organizations, commented that VR journalism needed more collaboration between the journalist and the subject than traditional video journalism, even repetition of the action. The New York Times' production team emphasized that they went "through the film piece by piece to make sure that it fairly represented reality" (Sullivan 2015; Robitzski 2017). Many experts have emphasized the importance of transparency: that the journalists tell openly about the journalistic processes that preceded the output and what kind of decisions are made, especially relating to authenticity and ethics.

As the resolution of the immersive journalism experience still evolves, the question of reality versus virtual reality is getting even more serious. For example, the Finnish company Varjo developed their first headset with a display that delivers human-eye resolution: 60 pixels per degree, the equivalent of 20/20 vision (Varjo. com 2019).

What happens when the quality of virtual reality is the same as our own vision? Actually, one of the biggest challenges for the future of immersive journalism will be how to detect forgeries. There is already a special term, "deepfakes", coined for a new kind of digital hoax. Fillion (2018) defines deepfakes as "realistic videos created with artificial intelligence software". So far, the known cases of deepfakes have used a variety of technologies, for example faceswaps, creating a lip-syncing facial expression onto someone else's face (ibid.). The Wall Street Journal has been among the first to establish a special section called a Media Forensics Committee in order to tackle the deepfakes already evidenced in 2018. In 2019, it had about 20 members from different parts of the newsroom, including photo, video, editorial, R\&D, audience/analytics, and standards/ethics (Lomdatze 2019). Arguably, it is only a matter of time before deepfakes in the form of immersive journalism news or documentaries will be created and circulated.

\section{Ethical reviews as tools, increased awareness of emotional data}

It has been interesting to note the findings of reviews into immersive technologies and how these may inform future practices. In 2019, a six-month inquiry was held by the UK Government into Immersive and Addictive Technologies. The recommendations included calling for technology companies to look at how 
they protect the audience from harm, and for a new "Online Harms" regulator that would hold social media platforms accountable for content or activity that harms individual users. Alongside this, there must be clear procedures to take down misleading "deepfake" videos. This may have an impact for developments within immersive journalism as technology evolves and more interactivity and social interactions within the news stories emerge.

Furthermore, as the platform companies are already seriously investing in the future of immersive technologies such as virtual reality, it is important also to start ethical discussions about their practices, especially in terms of emotional data collection. For example, by signing Facebook's data use policy the users potentially expose themselves to various experiments that could target, for instance, the users' emotions without informed consents (Jouhki et al. 2016, 79-81). As the tech companies have their own ethical rules and practices, and business secrets, critical academic research should continuously emphasize the importance of ethical questions in terms of the use of new technologies.

\section{Global co-learning on immersive journalism is growing}

It is important to add that global online networks and communities like special Facebook groups or ad-hoc Twitter accounts continuously foster and curate our knowledge about the new implications of virtual, augmented, and mixed reality in journalism. These virtual social media communities are increasingly identified as important global education hubs and information networks for immersive journalism.

One of the largest online communities focusing on VR is a Facebook group called Virtual Reality with more than 50,000 members in September 2019, seven years after it was started. There are also plenty of niche groups in social media platforms, like a Facebook group named as Film 360VR/MR - Los Angeles, which spreads across wider California. The group was founded in August 2017 and it had almost 400 members in September 2019. The main aims of this group are to 1) explore immersive media through interactive and robust events, 2) inform members about new tools and workflows at the intersection of media, entertainment, and technology, and 3) curate resources and solutions for immersive storytellers and innovators.

\section{Ways of storytelling are changing, eventually with the $5 \mathrm{C}$}

Many experts have argued that especially the fifth generation of cellular networks $(5 G)$ is needed before the immersive technologies will take off on a large scale. The New York Times launched among the very first newsrooms its 5G Journalism Lab in 2019. The company predicts that "Over the next few years, the transition to 5G will provide Internet speeds at least 20 times faster than $4 \mathrm{G}$ networks, enabling smartphones to download entire movies in seconds or stream massive multiplayer games without latency" (NYTimes.com 2019). 
When preparing this book we asked those working within immersive journalism for their thoughts on where the industry will be heading. What are their own ideas about how it may develop as the technological infrastructures and gadgets evolve?

Because of $5 \mathrm{G}$ and wearables, we're going to see an increasing intersection between biometric information and media. Users will be controlling media environments with their brainwaves and heart rate. In addition, media will be recommended to the user based on the data that's coming from their wearables.

Sarah Hill, Story-Up

I think the onset of $5 \mathrm{G}$ and the possibilities of immersive "glasses" that achieve what Google Glass couldn't may prove to be sparks that finally set this brand of journalism on fire. The one thing "traditional news" still can't do is put the viewer in the middle of the story. Well shot and produced 360 video can do that. Throw in all the other potential bells and whistles that VR and AR can offer, and I'm still convinced storytelling will be changed forever by this technology. Great work is being done, we just need a broad audience with the ability to watch it in its best form.

George Sells, MetroSTL.com

We tookVR on a tour this summer to 160 local libraries - slightly against my expectations the Congo films were the most appreciated by audiences - so that's a great endorsement of the power of VR journalism.

Zillah Watson, BBC

Predictions are particularly hard in the immersive field, even for 5 years in the future, because, if you glimpse back 5 years ago, you will be baffled at how fast hardware, software and content have evolved. One thing is clear for the next five years though, if they hope to reach the Promised Land of a mainstreamed technology, hardware manufacturers, software companies and content producers must put the audience at the centre of every decision they make from now on.

Thomas Seymat, VR editor at Euronews, RJI Fellow 2018-2019

\section{The promises of immersive journalism are still pertinent}

Immersive journalism is an evolving field. This book draws together research from scholars around the world highlighting the opportunities that the field presents, while acknowledging the challenges and concerns it brings as well. With greater adoption and the potential of 5G, the field may find many new users but most likely only as an addition to a growing portfolio of journalistic platforms. 
Clearly, there is a need for more research about the importance and role of online communities in terms of adapting to new emergent technologies in journalism, as well as the ethical challenges that this medium presents. Immersive journalism has the potential to reach new audiences, change the way stories are told, and provide more interactivity within the news industry.

\section{References}

Berry, Richard. 2015. "A Golden Age of Podcasting? Evaluating Serial in the Context of Podcast Histories." Journal of Radio \& Audio Media 22(2): 170-178.

Berry, Richard. 2016. "Podcasting: Considering the Evolution of the Medium and its Association with the Word 'Radio'." The Radio Journal: International Studies in Broadcast E Audio Media 14(1): 7-22. doi:10.1386/rajo.14.1.7_1

Bottomley, Andrew J. 2015. "Podcasting: A Decade in the Life of a 'New' Audio Medium: Introduction." Journal of Radio \& Audio Media 22(2): 164-169.

Evans, Leighton. 2019. The Re-Emergence of Virtual Reality. 1st ed. London: Routledge.

Fillion, Rubina M. 2018. "Fighting the Reality of Deepfakes. Predictions for Journalism 2019." Niemanlab.org [Accessed 19 December 2019].

Gauntlett, Jane. 2016. "In My Shoes: Intimacy. A Virtual Reality Experience for Two." https://jane-gauntlett.squarespace.com/ [Accessed 5 January 2020].

Hammersley, Ben. 2004. "Audible revolution." The Guardian. www.theguardian.com/media/ 2004/feb/12/broadcasting.digitalmedia [Accessed 14 October 2019].

ImmerseUK. 2018. "Immersive Economy Report.” www.immerseuk.org/resources/immersive_economy_report/ [Accessed 15 March 2020].

Jaekel, Brielle. 2015. "NY Times' VR Play is Publisher's Most Successful App Launch." Mobile Marketer, 12 November. www.mobilemarketer.com/cms/news/video/21676. html [Accessed 14 October 2019].

Jouhki,Jukka, Epp Lauk, Maija Penttinen, Niina Sormanen, \& Turo Uskali. 2016. "Facebook's Emotional Contagion Experiment as a Challenge to Research Ethics." Media and Communication 4(4), October: 75-85.

Lievrouw, Leah, A. 2014. "Materiality and Media in Communication and Technology Studies: An Unfinished Project." In: Tarleton Gillespie, Pablo J. Boczkowski, \& Kirsten A. Foot. Media Technologies: Essays on Communication, Materiality and Society. Cambridge; London:The MIT Press.

Lomdatze, Ana. 2019. “The WSJ on DeepFakes. 'It's a Cat and Mouse Game'." Medium. com/Global Editors Network. https://medium.com/global-editors-network/wsj-ondeepfakes-its-a-cat-mouse-game-212c3c7c6a4 [Accessed 14 October 2019].

McLuhan, Marshall \& Eric McLuhan. 1988. Laws of Media. University of Toronto Press.

Milk, C. 2015. "HowVirtual Reality Can Create the Ultimate Empathy Machine." TED Talk, March. www.ted.com/talks/chris_milk_how_virtual_reality_can_create_the_ultimate_ empathy_machine?utm_campaign1/4linkplug\&utm_source1/4linkplug\&utm_ medium1/4linkplug\&utm_content1/4linkplug\&utm_term1/4linkplug\#t-5120 [Accessed 15 March 2020].

Nielsen, S.L. \& P. Sheets. 2019. “Virtual Hype Meets Reality: Users' Perception of Immersive Journalism.” Journalism. https://doi.org/10.1177/1464884919869399.

NYTimes.com. 2019."Exploring the Future of 5G and Journalism.” https://open.nytimes.com/ exploring-the-future-of-5g-and-journalism-a53f4c4b8644 [Accessed 14 October 2019]. 
Robitzski, Dan. 2017. "Virtual Reality and Journalistic Ethics: Where Are the Lines?" Undark.org, 27 September. https://undark.org/article/virtual-reality-and-journalisticethics-where-are-the-lines/ [Accessed 15 March 2020].

Steed, Anthony, Ye Pan, Zillah Watson, \& Mel Slater. 2018. “We Wait': The Impact of Character Responsiveness and Self Embodiment on Presence and Interest in an Immersive News Experience." Frontiers in Robotics and AI 5.

Sullivan, M. 2015. “The Tricky Terrain of Virtual Reality." The New York Times. www.nytimes. com/2015/11/15/public-editor/new-york-times-virtual-reality-margaret-sullivanpublic-editor.html [Accessed 9 March 2019].

Varjo.com. 2019. https://varjo.com/ [Accessed 14 October 2019].

Watson, Z. 2017. VR for News: The New Reality? Digital News Project. Oxford, UK: Reuters Institute for the Study of Journalism, University of Oxford, p. 37. https://reutersinstitute. politics.ox.ac.uk/our-research/vr-news-new-reality [Accessed 15 March 2020]. 